\title{
Índice de Gestão Municipal em Cultura
}

Rogério Boueri

\section{Introdução}

A gestão municipal vem sendo objeto de crescente interesse dos estudiosos preocupados com a efetividade e o custo das políticas públicas. Isso porque, a partir da promulgação da Constituição de 1988, cada vez mais responsabilidades vêm sendo atribuídas aos governos municipais. Portanto, a sua capacidade de fazer frente a essas responsabilidades de forma satisfatória tem ganhado relevo no âmbito da administração pública brasileira.

Um dos passos mais elementares para que a atuação dos executivos municipais possa ser avaliada é a mensuração, por meio de variáveis relevantes, de indicadores capazes de sintetizar os diversos aspectos dessa gestão. A formulação de um índice específico para a área de cultura se insere, então, nesse esforço.

Os indicadores podem ser de grande valia na formulação de políticas públicas bem como em sua avaliação, mas é importante frisar que têm de ser concebidos dentro de um arcabouço no qual os objetivos das políticas já tenham sido 
definidos previamente. Nesse sentido, um indicador de educação, por exemplo, pode ser usado para mapear o estado da educação no Brasil, para avaliar se determinadas políticas estão atingindo os níveis de efetividade desejados etc. No entanto, ele não define a política educacional em si, isto é, se a sociedade deseja a universalização da educação, se a política de cotas para minorias é desejável e assim por diante.

O mesmo ocorre com um índice de gestão em cultura. A sua construção parte de conceitos preestabelecidos como positivos ao desenvolvimento da cultura no âmbito municipal, isto é, ele embute uma valoração prévia dos instrumentos de gestão. Por exemplo, no Índice de Gestão Municipal em Cultura (IGMC), que é apresentado neste trabalho, considerou-se que a gestão realizada por funcionários municipais permanentes é preferível àquela desempenhada por colaboradores contratados temporariamente; que maior frequência nas reuniões dos Conselhos de Cultura municipais implica maior clareza e transparência na gestão cultural etc. Portanto, o IGMC busca refletir um paradigma de gestão pública que valoriza a institucionalização da administração.

No entanto, depois de estabelecidas tais diretrizes, a metodologia de produção do índice tenta minimizar o nível de arbitrariedade no processo de cálculo. Para tanto, é utilizado o método de análise de componentes principais, o qual estabelece os pesos das diversas variáveis endogenamente, não sendo necessário ao pesquisador arbitrar tais valores.

Neste artigo, inicialmente, serão apresentados os princípios norteadores da formulação do Índice de Gestão Municipal em Cultura. Na seção seguinte, a metodologia de cálculo é pormenorizada, enquanto que, logo após, as variáveis integrantes de cada subíndice são especificadas. Na penúltima seção são apresentados os resultados obtidos e na última, possíveis aplicações do IGMC são exploradas. Ressalte-se que no Apêndice 1 estão descritos nos resultados mais detalhados.

\section{Princípios norteadores}

No presente trabalho, procurou-se construir índices para mensurar a gestão municipal do setor de cultura. É válido destacar que ele não tem por objetivo medir oferta, acesso ou fruição de cultura nos municípios brasileiros. O objetivo é avaliar se as prefeituras dispõem dos meios necessários para atuar na área de cultura e se elas efetivamente o fazem.

O princípio básico é o de que, se a prefeitura tem elementos para gerir adequadamente o setor, o acesso da população à cultura será ampliado, bem como a fruição cultural, que são, ao fim e ao cabo, o objetivo da intervenção governamental nesse caso.

Este relatório descreve a construção de um Índice de Gestão Municipal em Cultura (IGMC), o qual é subdividido em outros índices mais específicos, cuja utilização também pode ter propósitos individualizados.

O primeiro destes subíndices é o de Fortalecimento Institucional e Gestão Democrática da Cultura. Muitas vezes uma boa gestão em cultura (ou em qualquer outra área) depende da capacidade ou do interesse do prefeito ou de algum secretário em particular. Quando a administração municipal é substituída, a ênfase antes dada ao setor desaparece. Essa descontinuidade é tão mais provável quanto menos institucionalizada for a gestão cultural no município. Assim, a existência de instituições que preservem 
a prioridade do setor através de várias administrações é fato positivo para a gestão cultural, pois favorece a continuidade e o seu crescimento. Houve também a tentativa de mensurar o nível de democratização da gestão cultural dos municípios. Neste caso, foi valorizado o princípio de que quanto mais a população participa das decisões de gestão, mais efetiva será a ação em prol da cultura no município.

O segundo subíndice é o Índice de Infraestrutura e Recursos Humanos. Nele se tenta averiguar a qualidade da máquina municipal voltada para a gestão de cultura. Naturalmente, quanto maior a quantidade e a qualidade de pessoas envolvidas e dos equipamentos disponíveis, maior o desenvolvimento da gestão cultural.

Por fim, também foi produzido um Índice de Ação Cultural do município. Tal subíndice tem característica diversa dos demais, uma vez que, enquanto aqueles se preocupam com o processo ou os meios da gestão cultural do município, este último visa mensurar a participação efetiva do município na área cultural, ou seja, os produtos por ele oferecidos.

\section{Metodologia}

A construção do Índice de Gestão Municipal em Cultura, bem como a dos subíndices, utilizou a metodologia da Análise de Componentes Principais (ACP). Esta metodologia permite que os pesos de cada uma das variáveis envolvidas sejam determinados pela própria amostra, evitando assim o processo altamente subjetivo de atribuição de pesos pelo próprio pesquisador. É válido ressaltar que a metodologia ACP - aliás, como qualquer outra - não elimina a subjetividade, mas tão somente a reduz.
Em primeiro lugar, o questionário do Perfil dos Municípios Brasileiros, 2006/ Suplemento de Cultura (Munic) foi analisado em busca de variáveis que pudessem se integrar a cada um dos subíndices. Essa publicação do IBGE apresenta um retrato detalhado da administração cultural dos municípios brasileiros, pois, além dos resultados de cada prefeitura, traz uma série de agregações por tamanho de município e por região geográfica, que permite comparações interessantes [ver IBGE (2006)].

"Se a prefeitura tem elementos para gerir adequadamente o setor, o acesso da população à cultura será ampliado, bem como a fruição cultural [...]"

Ela é composta por 451 itens, os quais correspondem a respostas autodeclarativas das prefeituras.

Em seguida, foram atribuídos pontos a cada tipo de resposta de cada variável escolhida, procurando-se estabelecer uma gradação para as respostas, de modo que respostas associadas a situações menos desejadas obtivessem menos pontos do 
que aquelas que espelhassem situações consideradas mais vantajosas. Em alguns casos, mais de uma pergunta do questionário foi mesclada para a obtenção de uma variável. A seção "Variáveis utilizadas" descreve os pormenores do processo.

Todas as variáveis foram normalizadas de forma que cada uma das resultantes possuísse média zero e variância unitária. Esse processo foi empregado por dois motivos. Primeiro, porque a utilização do ACP tenderá a dar mais peso para variáveis com maior variância. A utilização das variáveis não normalizadas poderia distorcer os resultados, uma vez que uma série de fatores espúrios, como a unidade de medida da variável ${ }^{1}$, influencia a magnitude da variância. Segundo, como as escalas de pontuação são arbitrariamente escolhidas, tal arbitrariedade seria transferida para os índices, caso as variáveis não passassem pelo processo de normalização.

Uma vez que as variáveis componentes de cada subíndice foram escolhidas e devidamente normalizadas, procedeu-se a aplicação da ACP para obtenção de cada subíndice. Os subíndices são, por sua vez, também normalizados e escalonados para que não haja valores negativos. A obtenção do Índice de Gestão Municipal em Cultura é então atingida pela média aritmética dos subíndices calculados.

\section{Variáveis utilizadas}

As variáveis utilizadas foram todas extraídas da publicação Perfil dos Municípios Brasileiros, 2006 (Munic 2006). Tais variáveis foram adaptadas tanto para atender ao propósito de mensurar a capacidade municipal na gestão em cultura quanto para atender aos requisitos metodológicos e estatísticos utilizados.
A base da Munic dispõe de informação para 5.562 municípios, pois os municípios de São João da Ponte (MG) e São Luís Gonzaga do Maranhão (MA) não forneceram informações para a pesquisa, tendo sido excluídos dos cálculos dos índices.

\section{Subíndice de Fortalecimento} Institucional \& Gestão Democrática

- FI01 - Característica do órgão municipal gestor de cultura: para a obtenção dessa variável foi utilizada a Questão 1 do Bloco 03 da Munic (variável A2 no banco de dados da Munic) que pergunta sobre a estrutura do órgão municipal gestor de cultura. Foram associados os seguintes valores para as respostas disponíveis no questionário:

- Não possui estrutura específica (item 6): 0 ponto;

- Setor subordinado diretamente à chefia do executivo (item 4): 1 ponto;

- Setor subordinado a outra secretaria (item 3): 2 pontos;

- Secretaria municipal em conjunto com outras políticas setoriais (item 2): 3 pontos;

- Secretaria municipal exclusiva (item 1) ou fundação pública (item 5): 4 pontos.

Tal pontuação está baseada na percepção de que a melhor situação para a gestão cultural no município ocorre quando este dispõe de uma secretaria exclusiva ou fundação para gerir a cultura, uma vez que esse órgão estará mais apto a definir prioridades e objetivos e a implantar políticas visando alcançá-los. Naturalmente, reconhece-se que, em muitos municípios de menor porte, o estabelecimento de uma secretaria exclusiva para a cultura não seria prioridade, devido à pequena estrutura da administração municipal. 
A segunda melhor situação ocorre quando a gestão municipal da cultura é realizada por órgão multissetorial, supondo-se que, nesse caso, os interesses dos diversos setores tenham pesos semelhantes dentro da secretaria.

Uma situação menos favorável ocorre quando a gestão cultural está subordinada à secretaria de outro setor. É razoável supor que as prioridades da gestão cultural sejam relegadas a segundo plano em relação àquelas do setor primordial da secretaria.

A gestão cultural diretamente subordinada à chefia do executivo municipal é fato considerado ainda pior, pois existe uma tendência a que tal situação induza à utilização da cultura municipal primordialmente para promoção pessoal do prefeito e de sua administração.

A pior situação, no entanto, foi assinalada quando da não existência de estrutura específica para a gestão cultural. Nesse caso, fica explícita a falta de organização setorial dentro da prefeitura.

- FI02 - Existência de política municipal de cultura: para a obtenção da variável utilizou-se a Questão 1 do Bloco 06 da Munic (variável A56 no banco de dados da Munic), que pergunta sobre a existência de política municipal de cultura. Foram associados os seguintes valores para as respostas disponíveis no questionário:

- Não existe política municipal de cultura (item 2): 0 ponto;

- Existe política municipal de cultura (item 1): 1 ponto.

A existência de política municipal de cultura reflete maior institucionalização da gestão do setor, uma vez que tal política deve ser necessariamente fruto de planejamento e estabelecimento de objetivos.

- FI03 - Adesão do município ao Sistema Nacional de Cultura: variável obtida a partir da Questão 4 do Bloco 06 da Munic (variável A95 no banco de dados da Munic), que pergunta se o município aderiu ao Sistema Nacional de Cultura. Foram associados os seguintes valores para as respostas disponíveis no questionário:

- Município não aderiu ao Sistema Nacional de Cultura (questão 4, item 2): 0 ponto.

- Município aderiu ao Sistema Nacional de Cultura (questão 4, item 1): 1 ponto.

A adesão do município ao Sistema Nacional de Cultura reflete a participação em uma política nacional coordenada, o que, por sua vez, sugere um nível de institucionalização mais elevado.

- FI04 - Participação em consórcios intermunicipais de cultura: essa variável foi obtida a partir das Questões 6 e 8 do Bloco 06 da Munic (variáveis A97 e A99 a A103 no banco de dados da Munic), que pergunta se o município participa de consórcio intermunicipal de cultura e quais as atividades desenvolvidas em consórcio, respectivamente. Foram associados os seguintes valores para as respostas disponíveis no questionário:

- O município não participa de consórcios intermunicipais de cultura (questão 6, item 2): 0 ponto;

- Para cada atividade desenvolvida no âmbito do consórcio é atribuído um ponto (questão 8), podendo totalizar até 5 pontos.

Aqui se supõe que um maior número de atividades desenvolvidas de forma consorciada traga mais dinamismo à gestão cultural do município, bem como maior vinculação institucional.

- FI05 - Existência, estado e elaboração do Plano Municipal ou Intermunicipal de Cultura: a variável foi obtida a partir das Questões 9 e 10 do Bloco 06 da Munic (variáveis A104 e A105 no banco 
de dados da Munic), que perguntam se o município possui Plano Municipal ou Intermunicipal de Cultura e se este está em fase de implantação ou execução, respectivamente. Foram associados os seguintes valores para as respostas disponíveis no questionário:

- O município não possui plano municipal ou intermunicipal de cultura (questão 9, item 2): 0 ponto;

- O município possui plano municipal ou intermunicipal de cultura em fase de implantação (questão 9, item 1 e questão 10, item 1): 1 ponto;

- O município possui plano municipal ou intermunicipal de cultura em fase de execução (questão 9, item 1 e questão 10, item 2): 2 pontos;

A pontuação nessa variável se deu primeiramente pela existência ou não de plano municipal ou intermunicipal de cultura. Depois foi avaliado se o município já executa tal plano. No caso, a existência do plano, apesar de ser positiva indica metade do caminho andado, pois a implementação seria o objetivo final.

- FI06 - Participação social na elaboração do Plano Municipal ou Intermunicipal de Cultura: para a obtenção da variável foi utilizada a Questão 11 do Bloco 06 da Munic (variável A106 no banco de dados da Munic). Foram associados os seguintes valores para as respostas disponíveis no questionário:

- Não há Plano Municipal ou Intermunicipal de Cultura: 0 ponto;

- A sociedade civil não participou da elaboração do Plano Municipal ou Intermunicipal de Cultura (item 2): 1 ponto;

- A sociedade civil não participou da elaboração ou não há Plano Municipal ou Intermunicipal de Cultura (item 1): 2 pontos.
O nível de participação social está associado à democracia na gestão. Portanto, além da existência do plano, a participação da sociedade na sua elaboração também é desejada.

- FI07 - Existência e aplicação de Lei Municipal de fomento à cultura: variável obtida a partir das Questões 1 e 3 do Bloco 07 da Munic (variáveis A107 e A110 no banco de dados da Munic), que perguntam se existe no município lei de fomento à cultura, se esta foi aplicada nos últimos dois anos. Foram associados os seguintes valores para as respostas disponíveis no questionário:

- O município não possui lei municipal de fomento à cultura (questão 1, item 2): 0 ponto;

- O município possui lei municipal de fomento à cultura, mas ela não foi aplicada nos últimos dois anos (questão 1, item 1 e questão 3, item 2): 1 ponto;

- O município possui lei municipal de fomento à cultura e ela foi aplicada nos últimos dois anos (questão 1, item $1 \mathrm{e}$ questão 3, item 1): 2 pontos.

Aqui se presume que a ausência de lei é o pior cenário, sendo seguido, em ordem crescente, pelo cenário no qual a lei existe, mas não é aplicada, e pela situação na qual a lei existe e é aplicada.

- FI08 - Existência de lei municipal de proteção ao patrimônio histórico: variável obtida a partir da Questão 6 do Bloco 07 da Munic (variável A120 no banco de dados da Munic), que pergunta se existe lei municipal de proteção ao patrimônio histórico. Foram associados os seguintes valores para as respostas disponíveis no questionário:

- O município não possui lei municipal de proteção ao patrimônio histórico (item 2): 0 ponto; 
- O município possui lei municipal de proteção ao patrimônio histórico (item 1): 1 ponto.

A existência de lei municipal de proteção ao patrimônio histórico reflete maior grau de institucionalização da gestão cultural no município.

- FI09 - Existência e periodicidade dos encontros do Conselho Municipal de Cultura: variável obtida a partir das Questões 1 e 6 do Bloco 08 da Munic (variáveis A130 e A151 no banco de dados da Munic), que pergunta sobre a existência de Conselho Municipal de Cultura e sobre a periodicidade com que este se reúne. Foram associados os seguintes valores para as respostas disponíveis no questionário:

- O município não possui Conselho Municipal de Cultura (questão 1, item 2 ): 0 ponto;

- O município possui Conselho Municipal de Cultura, mas este não se reuniu nos últimos 12 meses (questão 1, item 1 e questão 6, item 6): 1 ponto; - O município possui Conselho Municipal de Cultura, mas este se reuniu com frequência irregular nos últimos 12 meses (questão 1, item 1 e questão 6, item 5): 2 pontos;

- O município possui Conselho Municipal de Cultura e este se reuniu com frequência anual nos últimos 12 meses (questão 1, item 1 e questão 6, item 4): 3 pontos;

- O município possui Conselho Municipal de Cultura e este se reuniu com frequência quadrimestral ou semestral nos últimos 12 meses (questão 1, item 1 e questão 6, item 3): 4 pontos;

- O município possui Conselho Municipal de Cultura e este se reuniu com frequência bimestral ou trimestral nos últimos 12 meses (questão 1, item 1 e questão 6 , item 2): 5 pontos;
- O município possui Conselho Municipal de Cultura e este se reuniu pelo menos com frequência mensal nos últimos 12 meses (questão 1, item $1 \mathrm{e}$ questão 6 , item 1): 6 pontos.

Uma das maiores indicações de gestão democrática em um município é a existência de conselhos municipais. Naturalmente que a mera existência destes não significa necessariamente que haja participação efetiva na gestão, mas a sua ausência provavelmente

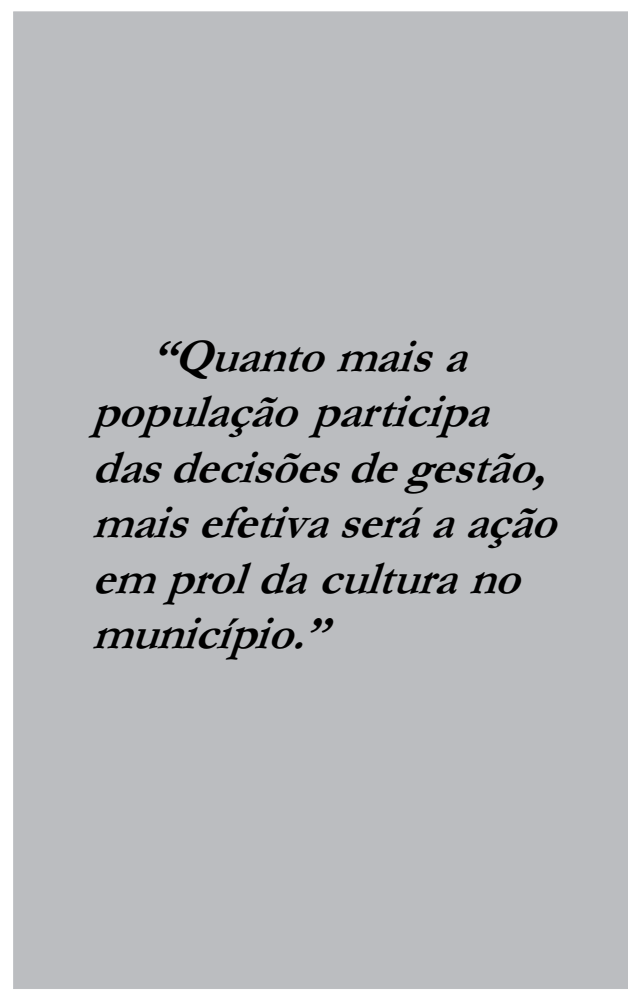

atesta a carência de transparência. Por este motivo se considera que é preferível ter um Conselho de Cultura, mesmo que este nunca tenha funcionado, do que não tê-lo. Contudo, quanto maior a sua frequência de encontros, mais atuante e significativo será julgado o fortalecimento institucional do conselho.

- FI10 - Estrutura do Conselho Municipal de Cultura: para a obtenção dessa 
variável foi utilizada a Questão 3 do Bloco 08 da Munic (variável A137 no banco de dados da Munic). Foram associados os seguintes valores para as respostas disponíveis no questionário:

- Não há conselho: 0 ponto;

- O conselho tem maior representação governamental (item 2): 1 ponto;

- O conselho tem representação paritária (item 1): 2 pontos;

- O conselho tem maior representação da sociedade civil (item 3): 3 pontos.

Nessa variável buscou-se uma gradação de menor representação da sociedade civil para maior representação. A representação paritária é o ponto intermediário. A falta do conselho por si demonstra menor democracia na gestão da cultura.

- FI11 - Escolha dos participantes do Conselho Municipal de Cultura advindos da sociedade civil: para a obtenção dessa variável foi utilizada a Questão 4 do Bloco 08 da Munic (variável A138 no banco de dados da Munic). Foram associados os seguintes valores para as respostas disponíveis no questionário:

- Não há conselho: 0 ponto;

- Indicação do poder público (item 2): 1 ponto;

- Indicação do poder público e da sociedade civil ou "Outras" (itens 3 e 4): 2 pontos;

- Indicação da sociedade civil (item 3): 3 pontos.

A indicação da sociedade civil é valorizada por suscitar independência do Conselho em relação ao Executivo local. No caso da respostas "Outras", considerou-se um caso assemelhado à indicação mista, visto que não há preponderância explícita de indicação do poder público.

- FI12 - Diversificação da representação da sociedade civil no Conselho
Municipal de Cultura: para a obtenção da variável foi utilizada a Questão 5 do Bloco 08 da Munic (variáveis A139 a A150 no banco de dados da Munic). Foram associados os seguintes valores para as respostas disponíveis no questionário:

- Não há conselho: 0 ponto;

- Para cada setor da sociedade civil representado é atribuído um ponto (questões 5.1 a 5.12), podendo totalizar até 12 pontos.

Nessa variável é valorizada a diversificação do Conselho de Cultura - quanto mais setores estiverem representados maior a pontuação do município.

- FI13 - Diversificação das atribuições do Conselho Municipal de Cultura: para a obtenção da variável foi utilizada a Questão 7 do Bloco 08 da Munic (variáveis A152 a A163 no banco de dados da Munic). Foram associados os seguintes valores para as respostas disponíveis no questionário:

- Não há conselho: 0 ponto;

- Para cada atribuição do conselho é atribuído um ponto (questões $7.1 \mathrm{a}$ 7.12), podendo totalizar até 12 pontos.

Supõe-se que quanto mais diversificadas as atribuições do conselho maior a democratização da gestão cultural no município.

- FI14 - Existência e periodicidade dos encontros do Conselho Municipal de Preservação do Patrimônio: variável obtida a partir das Questões 8 e 13 do Bloco 08 da Munic (variáveis A164 e A185 no banco de dados da Munic) que pergunta sobre a existência de Conselho Municipal de Preservação do Patrimônio e sobre a periodicidade com que este se reúne. Foram associados os seguintes valores para as respostas disponíveis no questionário:

- O município não possui conselho Municipal de Preservação do Patrimônio (questão 8, item 2): 0 ponto; 
- O município possui Conselho Municipal de Preservação do Patrimônio, mas este não se reuniu nos últimos 12 meses (questão 8, item $1 \mathrm{e}$ questão 13, item 6): 1 ponto;

- O município possui Conselho Municipal de Preservação do Patrimônio, mas este se reuniu com frequência irregular nos últimos 12 meses (questão 8, item 1 e questão 13, item 5): 2 pontos;

- O município possui Conselho Municipal de Preservação do Patrimônio e este se reuniu com frequência anual nos últimos 12 meses (questão 8, item 1 e questão 13, item 4): 3 pontos;

- O município possui Conselho Municipal de Preservação do Patrimônio e este se reuniu com frequência quadrimestral ou semestral nos últimos 12 meses (questão 8, item $1 \mathrm{e}$ questão 13, item 3): 4 pontos;

- O município possui Conselho Municipal de Preservação do Patrimônio e este se reuniu com frequência bimestral ou trimestral nos últimos 12 meses (questão 8, item $1 \mathrm{e}$ questão 13, item 2): 5 pontos;

- O município possui Conselho Municipal de Preservação do Patrimônio e este se reuniu pelo menos com frequência mensal nos últimos 12 meses (questão 8, item 1 e questão 13, item 1): 6 pontos.

Como no caso dos conselhos de Cultura, considerou-se que é preferível ter um Conselho Municipal de Preservação do Patrimônio mesmo que este nunca tenha funcionado do que não tê-lo. Quanto maior a frequência de encontros, mais atuante e significativo será julgado o fortalecimento institucional do conselho.

- FI15 - Estrutura do Conselho de Preservação do Patrimônio: para a obtenção desta variável foi utilizada a Questão 10 do Bloco 08 da Munic (variável A171 no banco de dados da Munic). Foram associados os seguintes valores para as respostas disponíveis no questionário:

- Não há conselho: 0 ponto;

- O conselho tem maior representação governamental (item 2): 1 ponto;

- O conselho tem representação paritária (item 1): 2 pontos;

- O conselho tem maior representação da sociedade civil (item 3): 3 pontos.

Nessa variável buscou-se uma gradação de menor representação da sociedade civil para maior representação. A representação paritária é o ponto intermediário. A falta do Conselho de Preservação do Patrimônio por si demonstra menor democracia na gestão da cultura.

- FI16 - Escolha dos participantes do Conselho Municipal de Preservação do Patrimônio advindos da sociedade civil: para a obtenção da variável foi utilizada a Questão 8 do Bloco 08 da Munic (variável A172 no banco de dados da Munic). Foram associados os seguintes valores para as respostas disponíveis no questionário:

- Não há conselho: 0 ponto;

- Indicação do poder público (item 2): 1 ponto;

- Indicação do poder público e da sociedade civil ou "Outras" (itens 3 e 4): 2 pontos;

- Indicação da sociedade civil (item 3): 3 pontos.

A indicação da sociedade civil é valorizada por suscitar independência do conselho em relação ao executivo local. No caso da respostas "Outras", considerou-se um caso assemelhado à indicação mista, visto que não há preponderância explícita de indicação do poder público. 
- FI17 - Diversificação da representação da sociedade civil no Conselho Municipal de Preservação do Patrimônio: para a obtenção desta variável foi utilizada a Questão 12 do Bloco 08 da Munic (variáveis A173 a A184 no banco de dados da Munic). Foram associados os seguintes valores para as respostas disponíveis no questionário:

- Não há conselho: 0 ponto;

- Para cada setor da sociedade civil representado é atribuído um ponto (questões 12.1 a 12.12), podendo totalizar até 12 pontos.

Nessa variável é valorizada a diversificação do Conselho de Preservação do Patrimônio - quanto mais setores estiverem representados, maior a pontuação do município.

- FI18 - Diversificação das atribuições do Conselho Municipal de Preservação do Patrimônio: para a obtenção da variável foi utilizada a Questão 14 do Bloco 08 da Munic (variáveis A186 a A195 no banco de dados da Munic). Foram associados os seguintes valores para as respostas disponíveis no questionário:

- Não há conselho: 0 ponto;

- Para cada atribuição do conselho é designado um ponto (questões 14.1 a 14.10), podendo totalizar até 10 pontos.

Supõe-se que maior diversificação das atribuições do conselho representa maior democratização da gestão cultural no município.

- FI19 - Existência e exclusividade do Fundo Municipal de Cultura: variável obtida a partir da Questão 1 do Bloco 09 da Munic (variáveis A196 e A199 no banco de dados da Munic), que pergunta sobre a existência de Fundo Municipal de Cultura e sobre a exclusividade deste. Foram associados os seguintes valores para as respostas disponíveis no questionário:
- O município não possui Fundo Municipal de Cultura (item 2): 0 ponto; - O município possui Fundo Municipal de Cultura, mas não exclusivo (subquestão 1.3, item 2): 1 ponto; - O município possui Fundo Municipal de Cultura exclusivo (subquestão 1.3, item 1): 2 pontos;

A existência do fundo associada à exclusividade de sua destinação à cultura é considerada a melhor situação, seguida daquela na qual o fundo existe, mas não é exclusivo da cultura. O pior cenário é o de inexistência do fundo. Isso porque o Fundo Municipal de Cultura refletiria maior autonomia e institucionalização da gestão cultural, posto que os recursos para projetos culturais seriam destacados do orçamento geral do município.

- FI20 - Administração do Fundo Municipal de Cultura: para a obtenção da variável foi utilizada a Questão 2 do Bloco 09 da Munic (variável A201 no banco de dados da Munic). Foram associados os seguintes valores para as respostas disponíveis no questionário:

- Não há fundo: 0 ponto;

- Administração do fundo realizada por secretário ou técnico de outra área, ou outro (itens 3 e 5): 1 ponto;

- Administração do fundo realizada por secretário ou técnico da área (item 4): 2 pontos;

- Administração do fundo realizada por colegiado diretor, sem participação da sociedade civil (item 2): 3 pontos;

- Administração do fundo realizada por colegiado diretor, com participação da sociedade civil (item 1): 4 pontos;

Nesse caso, a hierarquia das opções começa com a situação na qual o Fundo de Cultura possui colegiado diretor e este tem representação da sociedade civil. A segunda 
situação preferível é aquela na qual o fundo tem colegiado, mas sem participação. Aqui se supõe que o colegiado seja um passo na direção da gestão democrática. A seguir vêm as opções menos desejáveis de administração individual do fundo.

- FI21 - A seleção de projetos a serem financiados pelo Fundo Municipal de Cultura inclui concursos ou editais públicos: para a obtenção da variável foi utilizada a Questão 5 do Bloco 09 da Munic (variáveis A223 e A224 no banco de dados da Munic). Foram associados os seguintes valores para as respostas disponíveis no questionário:

- Seleção de projetos não é realizada por concurso ou edital público (questões 5.1 e 5.2): 0 ponto;

- Seleção de projetos é realizada por concurso ou edital público (questões 5.1 e 5.2): 1 ponto.

A seleção de projetos por concurso ou edital foi considerada a forma mais democrática, uma vez que abre oportunidades iguais para todos os concorrentes.

\section{Subíndice de Infraestrutura e Recursos Humanos}

- IH01 - Telefonia: para a obtenção da variável foi utilizada a Questão 1 do Bloco 04 da Munic (variável A4 no banco de dados da Munic), que pergunta sobre as condições de serviço telefônico disponíveis no órgão municipal responsável pela gestão de cultura. Foram associados os seguintes valores para as respostas ao questionário:

- Não possui linha telefônica instalada (item 4): 0 ponto;

- Não possui linha telefônica instalada, mas possui ramal (item 2): 1 ponto;

- Possui linha telefônica instalada com ou sem ramal (item 1): 2 pontos;

O objetivo aqui é o de obter uma gradação no nível de sofisticação e de operacionalidade dos equipamentos de telefonia disponíveis ao órgão gestor de cultura no município. O pressuposto é que a telefonia é um recurso valioso na gestão cultural por permitir uma comunicação efetiva com o público externo.

- IH02 - Disponibilidade de computadores: para a obtenção da variável foi utilizada a Questão 2 do Bloco 04 da Munic (variável A5 no banco de dados da Munic) que pergunta sobre o número

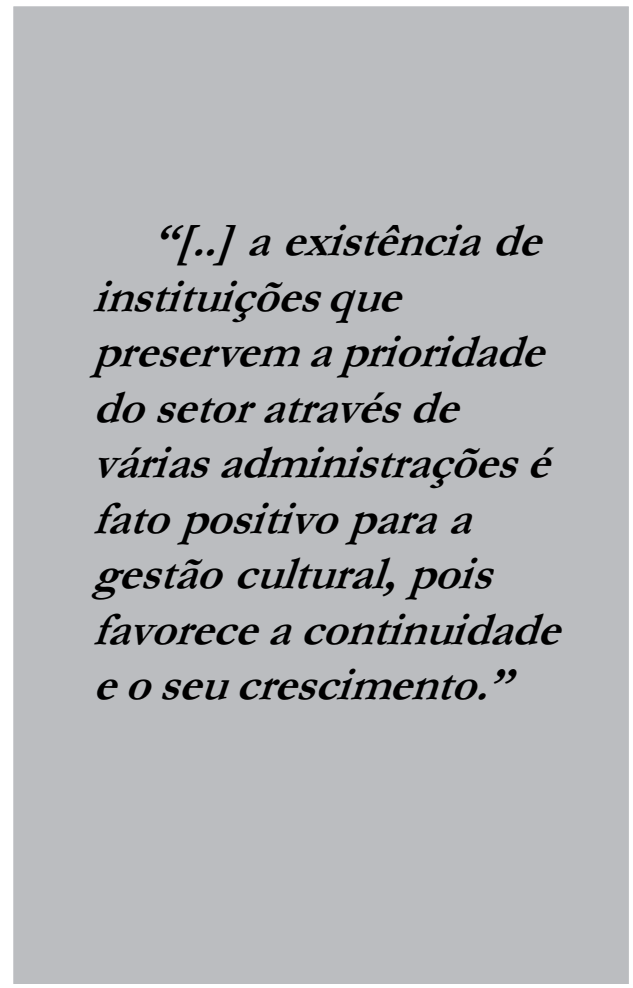

de computadores disponíveis à utilização do órgão gestor de cultura no município. Foram associados os seguintes valores para as respostas disponíveis no questionário:

- Nenhum (item 1): 0 ponto;

- Até 2 (item 2): 1 ponto;

- De 3 a 6 (item $3^{2}$ ): 2 pontos;

- De 6 a 10 (item 4): 3 pontos;

- Mais de 10 (item 5): 4 pontos. 
O objetivo aqui é obter uma gradação no nível de sofisticação e de operacionalidade dos equipamentos de informática disponíveis ao órgão gestor de cultura no município.

- IH03 - Existência e qualidade da conexão de internet: para a obtenção dessa variável foram utilizadas as Questões 3 e 4 do Bloco 04 da Munic (variáveis A6 e A7 no banco de dados da Munic) que pergunta sobre o número de computadores disponíveis à utilização do órgão gestor de cultura no município com acesso à internet e sobre o tipo de conexão utilizada. Foram associados os seguintes valores para as respostas ao questionário:

- Não possui acesso (questão 3, item 2): 0 ponto;

- Possui acesso discado (questão 3, item 1 e questão 4, item 1): 1 ponto;

- Possui acesso banda larga (questão 3, item 1 e questão 4, item 2): 2 pontos.

O objetivo aqui é obter uma gradação no nível de sofisticação e de operacionalidade do acesso à internet disponível ao órgão gestor de cultura no município.

- IH04 - Existência de página própria do órgão gestor: para a obtenção da variável foi utilizada a Questão 5 do Bloco 04 da Munic (variáveis A8 no banco de dados da Munic) que pergunta sobre a existência de página própria do órgão gestor na internet. Foram associados os seguintes valores para as respostas disponíveis no questionário:

- Não possui página própria (item 2):

0 ponto;

- Possui página própria (item 1): 1 ponto.

A existência de página própria do órgão gestor de cultura indica melhor infraestrutura.

- IH05 - Existência de página eletrônica, endereço eletrônico do órgão gestor: para a obtenção da variável foi utilizada a Questão 7 do Bloco 04 da Munic (variável A10 no banco de dados da Munic) que pergunta sobre a existência de e-mail do órgão gestor. Foram associados os seguintes valores para as respostas disponíveis no questionário:

- Não possui e-mail (item 2): 0 ponto;

- Possui e-mail (item 1): 1 ponto;

A existência de e-mail do órgão gestor de cultura indica melhor infraestrutura. Algumas das respostas não foram consideradas consistentes. Em particular, 18 municípios declararam ter página própria para o órgão gestor de cultura na internet, mas não possuir endereço eletrônico. Nesse caso, considerou-se a inexistência de página eletrônica para tais municípios.

- IH06 - Número de pessoas ocupadas na área de cultura na administração municipal ajustado pela população do município: para a obtenção da variável foi utilizada a Questão 2 do Bloco 05 (variável A14 no banco de dados da Munic), especificamente os valores registrados no item 2.6.6 e a população municipal estimada para 2006 (variável A450 no banco de dados da Munic).

A lógica desse indicador é que quanto maior o número de pessoas envolvidas na gestão cultural do município mais efetiva será sua infraestrutura. No caso de registros contendo "Ignorado" ou "Não Aplicável" foi assinalado o valor zero.

Existem, no entanto, diversas questões técnicas para a utilização dessa variável. Em primeiro lugar, é de se esperar que municípios maiores possuam mais pessoas trabalhando em gestão cultural. Contudo, esta proporção não é fixa, fazendo-se necessários ajustes para assegurar a coerência da variável.

- IH07 - Número de estatutários atuando na área de cultura na administração 
municipal ajustado pela população do município: para a obtenção da variável foi utilizada a Questão 2 do Bloco 05 da Munic (variável A15 no banco de dados da Munic), especificamente os valores registrados no item 2.1.6 e a população municipal estimada para 2006 (variável A450 no banco de dados da Munic).

A lógica do indicador é que quanto maior o número de funcionários de carreira atuando na gestão cultural do município, mais efetiva será sua infraestrutura. No caso de registros contendo "Ignorado" ou "Não Aplicável" foi assinalado o valor zero. Como na variável anterior, esta também passou pelos ajustes estatísticos necessários.

- IH08 - Número total de pessoas com nível superior atuando na área de cultura na administração municipal ajustado pela população do município: para a obtenção da variável foi utilizada a Questão 2 do Bloco 05 da Munic (soma das variáveis A19, A20, A25, A26, A31, A32, A40 e A41 no banco de dados da Munic), especificamente a soma dos valores registrados nos itens 2.6 .4 e 2.6 .5 e a população municipal estimada para 2006 (variável A450 no banco de dados da Munic).

A lógica do indicador é que quanto maior o número de funcionários com educação superior, mais efetiva será a infraestrutura na área. No caso de registros contendo "Ignorado" ou "Não Aplicável" foi assinalado o valor zero. Mais uma vez procederam-se os ajustes estatísticos necessários.

- IH09 - Despesa realizada em cultura no ano de 2005 ajustada pela população do município: para a obtenção da variável foi utilizada a Questão 1 do Bloco 10 da Munic (variável A230 no banco de dados da Munic), especificamente o valor registrado no item 2.1 e a população municipal estimada para 2006 (variável A450 no banco de dados da Munic).

Aqui se considerou que a maior disponibilidade de recursos financeiros é um fator para a melhoria dos recursos de infraestrutura administrativa. Além disso, a magnitude desses recursos deve também crescer com o tamanho da população. Foi utilizada a despesa executada para 2005 porque na base de dados disponibilizada em CD não constam os valores de 2006, muito embora tais valores estejam presentes no questionário. Valores computados como "Não disponível" e "Ignorado" na base de dados foram considerados nulos.

- IH10 - Despesa realizada em cultura no ano de 2005 como proporção da receita do município: para a obtenção da variável foi utilizada a Questão 1 do Bloco 10 da Munic (variáveis A229 e A230 no banco de dados da Munic), especificamente os valores registrados nos itens 2.1 e 4.1 , bem como a população municipal estimada para 2006 (variável A450 no banco de dados da Munic).

O ponto aqui é o de que municípios pobres não devem ser penalizados no índice pelo baixo volume absoluto de recursos disponíveis para a gestão cultural. $\mathrm{O}$ valor absoluto é então considerado de forma relativa à receita total do município.

\section{Subíndice de Ação Cultural}

- AC01 - Ações implementadas pela política municipal de cultura nos últimos 24 meses: para a obtenção da variável foram utilizadas as Questões 3.1 a 3.29 do Bloco 06 da Munic (variáveis A66 a A94 no banco de dados da Munic). Foi atribuído 1 ponto para cada tipo de ação implementada. Cada município pode somar até 29 pontos.

O objetivo dessa variável é valorizar a diversidade da ação municipal em cultura. 
Assim, quanto mais setores culturais diferentes forem abrangidos, maior será a pontuação do município. É válido notar que, apesar de a variável poder assumir valor de zero a 29, ela não terá a priori peso maior do que as outras, uma vez que todas são normalizadas.

- AC02 - Existência de cursos promovidos pela prefeitura na área de cultura: para a obtenção dessa variável foram utilizadas as Questões 1.1 a 1.7 do Bloco 12 da Munic (variáveis A250 a A256 no banco de dados da Munic). Foi atribuído 1 ponto para cada tipo de curso oferecido. Cada município pode somar até 7 pontos.

O mesmo princípio de diversidade cultural é aplicado nessa variável, bem como na variável AC03.

- AC03 - Existência de escola, oficinas ou cursos na área cultural mantidos pelo poder público municipal: para a obtenção da variável foram utilizadas as Questões 3.1.1 a 3.14.1 do Bloco 12 da Munic (variáveis ímpares entre A259 a A285 no banco de dados da Munic). Foi atribuído 1 ponto para cada modalidade oferecida. Cada município pode somar até 14 pontos.

- AC04 - Existência de projeto de implementação de turismo cultural na administração municipal: para a obtenção da variável foram utilizadas as Questões 4, 4.1, 5.1, 5.2, 5.3 e 5.4 do Bloco 12 da Munic (variáveis A286, A287, A288, A289, A290 e A291 no banco de dados da Munic). Foram associados os seguintes valores para as respostas ao questionário:

- Não há projeto de turismo cultural (questão 4, item 2): 0 ponto;

- Há projeto de turismo cultural gerido somente pela iniciativa privada (questão 4, item 1 e questão 5.3): 1 ponto; - Há projeto de turismo cultural gerido pelo setor público municipal em fase de implantação (questão 4, item 1, questão 4.1, item 1 e questões $5.1 \mathrm{ou}$ 5.2, ou 5.4): 2 pontos;

- Há projeto de turismo cultural gerido pelo setor público municipal em execução (questão 4, item 1, questão 4.1, item 2 e questões 5.1 ou 5.2, ou 5.4): 3 pontos.

Essa variável busca diferenciar projetos diretamente geridos pelo poder público daqueles de iniciativa privada (uma vez que estes possivelmente dependem menos da ação municipal), bem como aqueles em execução efetiva daqueles que ainda se encontram em fase de implementação.

- AC05 - Concursos culturais mantidos, patrocinados ou financiados pela administração municipal: para a obtenção da variável foram utilizadas as Questões 7.1.1 a 7.1.9 do Bloco 12 da Munic (variáveis ímpares entre A297 e A313 no banco de dados da Munic). Foi atribuído 1 ponto para cada modalidade oferecida. Cada município pode somar até 9 pontos.

Nessa variável, bem como nas que se seguem, também foi adotado o princípio de valorização da diversidade cultural, segundo o qual quanto maior o número de modalidades culturais apoiadas, maior a pontuação do município.

- AC06 - Festivais ou mostras culturais mantidos, patrocinados ou financiados pela administração municipal: para a obtenção da variável foram utilizadas as Questões 7.2.1 a 7.2.8 do Bloco 12 da Munic (variáveis ímpares entre A315 e A329 no banco de dados da Munic). Foi atribuído 1 ponto para cada modalidade oferecida. Cada município pode somar até 8 pontos.

- AC07 - Feiras culturais mantidas, patrocinadas ou financiadas pela administração municipal: para a obtenção da variável foram utilizadas as Questões 
7.3.1 a 7.3.5 do Bloco 12 da Munic (variáveis ímpares entre A331 e A339 no banco de dados da Munic). Foi atribuído 1 ponto para cada modalidade oferecida. Cada município pode somar até 5 pontos.

- AC08 - Exposições culturais mantidas, patrocinadas ou financiadas pela administração municipal: para a obtenção dessa variável foram utilizadas as Questões 7.4.1 a 7.4.6 do Bloco 12 da Munic (variáveis ímpares entre A341 e A351 no banco de dados da Munic). Foi atribuído 1 ponto para cada modalidade oferecida. Cada município pode somar até 6 pontos.

- AC09-Financiamento ou patrocínio de atividades culturais pela administração municipal nos últimos dois anos: para a obtenção da variável foram utilizadas as Questões 8.1 a 8.6 do Bloco 12 da Munic (variáveis pares entre A352 e A362 no banco de dados da Munic). Foi atribuído 1 ponto para cada modalidade oferecida. Cada município pode somar até 6 pontos.

- AC10 - Existência de grupos culturais mantidos pela administração municipal com, no mínimo, dois anos de atuação: para a obtenção dessa variável foram utilizadas as Questões 9.1.1 a 9.17.1 do Bloco 12 da Munic (variáveis pares entre A364 e A396 no banco de dados da Munic). Foi atribuído 1 ponto para cada modalidade oferecida. Cada município pode somar até 17 pontos.

- AC11 - Existência de equipamentos culturais mantidos pela administração municipal: para a obtenção dessa variável foram utilizadas as Questões 1.1.2 a 1.5.2 do Bloco 14 da Munic (variáveis A426, A429, A433, A436 e A4393). Foi atribuído 1 ponto para cada modalidade oferecida. Cada município pode somar até 5 pontos.

\section{Resultados obtidos}

\section{Pesos das variáveis nos subíndices}

Os pesos para a formação de cada subíndice e para o índice geral foram obtidos de acordo com os procedimentos descritos na seção de metodologia. Os pesos calculados para o Subíndice de Fortalecimento Institucional e Gestão Democrática estão descritos no Gráfico 1. O grau de explicação do subíndice em relação à variância das 20 variáveis utilizadas é de $32,9 \%$.

No Subíndice de Fortalecimento Institucional e Gestão Democrática, ocorre uma gradação nos pesos das variáveis a qual permitiria a sua separação por grupos. Do grupo de variáveis mais influentes fazem parte FI13, FI14, FI15, FI16 e FI17, cujos pesos oscilam próximos a 0,3. Essas variáveis são relacionadas com os Conselhos de Defesa do Patrimônio e indicam que instauração de melhorias no funcionamento desses conselhos poderiam aprimorar substancialmente o subíndice.

O segundo grupo de variáveis, cujos pesos flutuam em torno de 0,25 , é formado por FI07, FI08, FI09, FI11 e FI12. A maioria das variáveis é relacionada com o Conselho Municipal de Cultura. Por fim, o grupo de menor peso abrange as demais variáveis que têm menos influência na determinação do subíndice.

O Gráfico 2 mostra os pesos calculados para o Subíndice de Infraestrutura e Recursos Humanos. A variância deste subíndice reflete $30 \%$ da variância das variáveis envolvidas no seu cálculo.

Pode-se observar que as variáveis IH06, IH07 e IH08 são as mais influentes na determinação do subíndice, com pesos superiores a 0,55 . Essas variáveis são todas relativas a recursos humanos, fato indicativo de que a presença de 


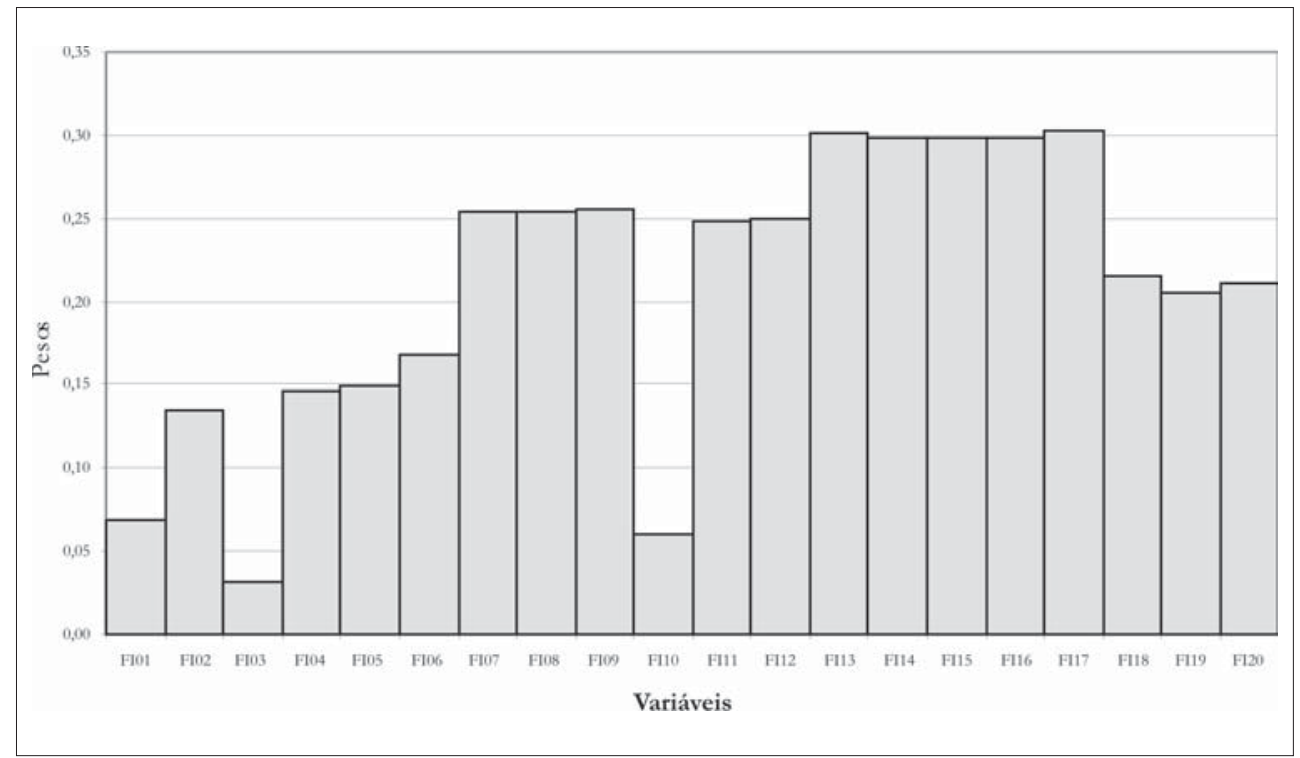

Fonte: Elaboração do autor

Gráfico 1: Pesos atribuídos às variáveis no cálculo do Subíndice de Fortalecimento Institucional e Gestão Democrática

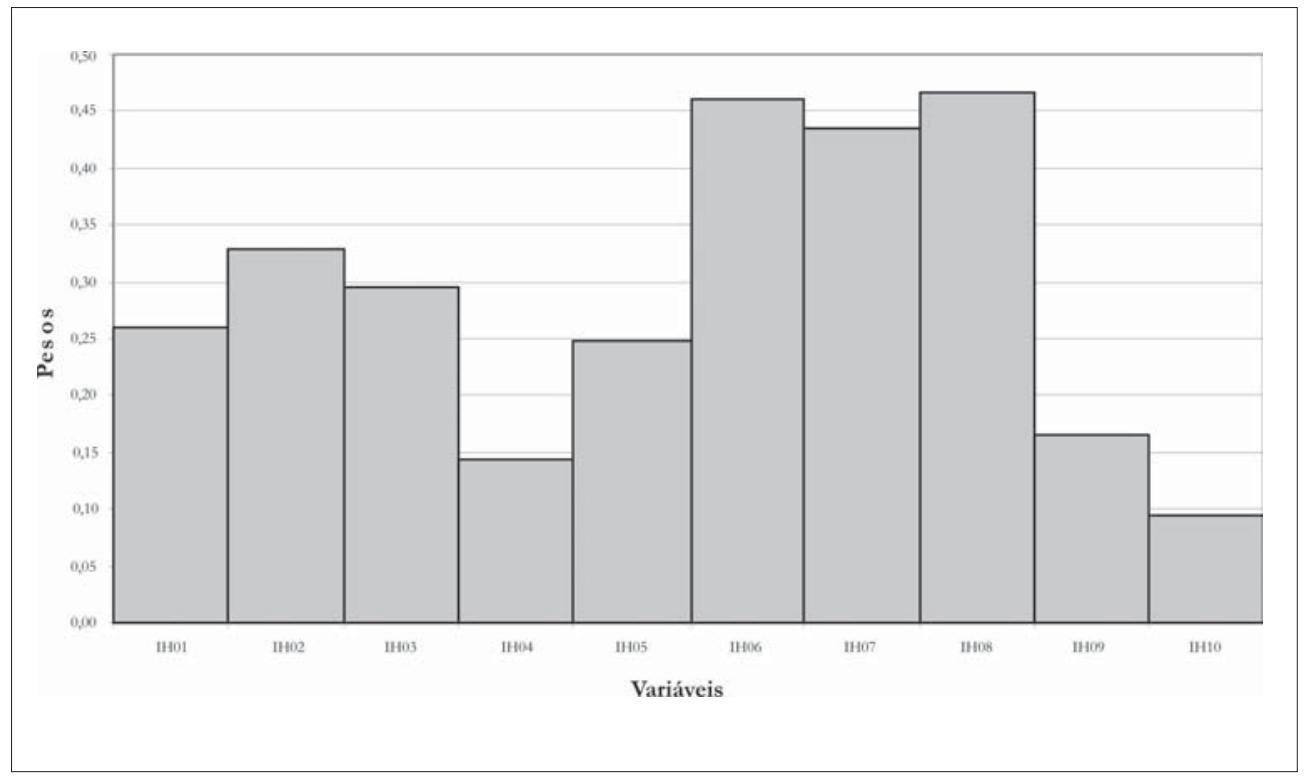

Fonte: Elaboração do autor

Gráfico 2: Pesos atribuídos às variáveis no cálculo do Subíndice de Infraestrutura e Recursos Humanos 
pessoal atuando na área cultural é o que diferencia os municípios segundo este subíndice. A variável IH09 (despesa em cultura ajustada pela população) também é significativa na ponderação, embora seu peso seja substancialmente inferior àqueles associados às variáveis do primeiro grupo.

As outras variáveis utilizadas na construção do subíndice tiveram pesos pequenos, chegando, no caso de $\mathrm{IH} 03$ (existência e qualidade da conexão de internet), a atingir um valor negativo, embora muito pequeno $(-0,01)$. Esse peso, que não é significativamente diferente de zero, talvez se deva ao fato de $70 \%$ dos municípios já possuírem internet banda larga, o que denotaria baixo poder de discriminação da variável.

De qualquer maneira, as variáveis de baixo peso são todas relacionadas à infraestrutura material do órgão municipal de cultura, atestando que não são fatores desse tipo que diferenciam os municípios de acordo com esse subíndice.

O Gráfico 3 descreve os pesos calculados para a construção do Subíndice de Ação Cultural. O poder explicativo desse subíndice, em relação à variância conjunta das 11 variáveis utilizadas na sua construção, é de $43,7 \%$.

Os pesos desse subíndice são distribuídos de forma bastante homogênea, ficando sua variação restrita entre um mínimo de 0,229 (AC04) a 0,348 (AC08). Tal fato indica que todas as variáveis utilizadas têm influência semelhante no índice.

\section{Rankings segundo os subíndices}

A Tabela 1 apresenta os dez melhores municípios de acordo com o Subíndice

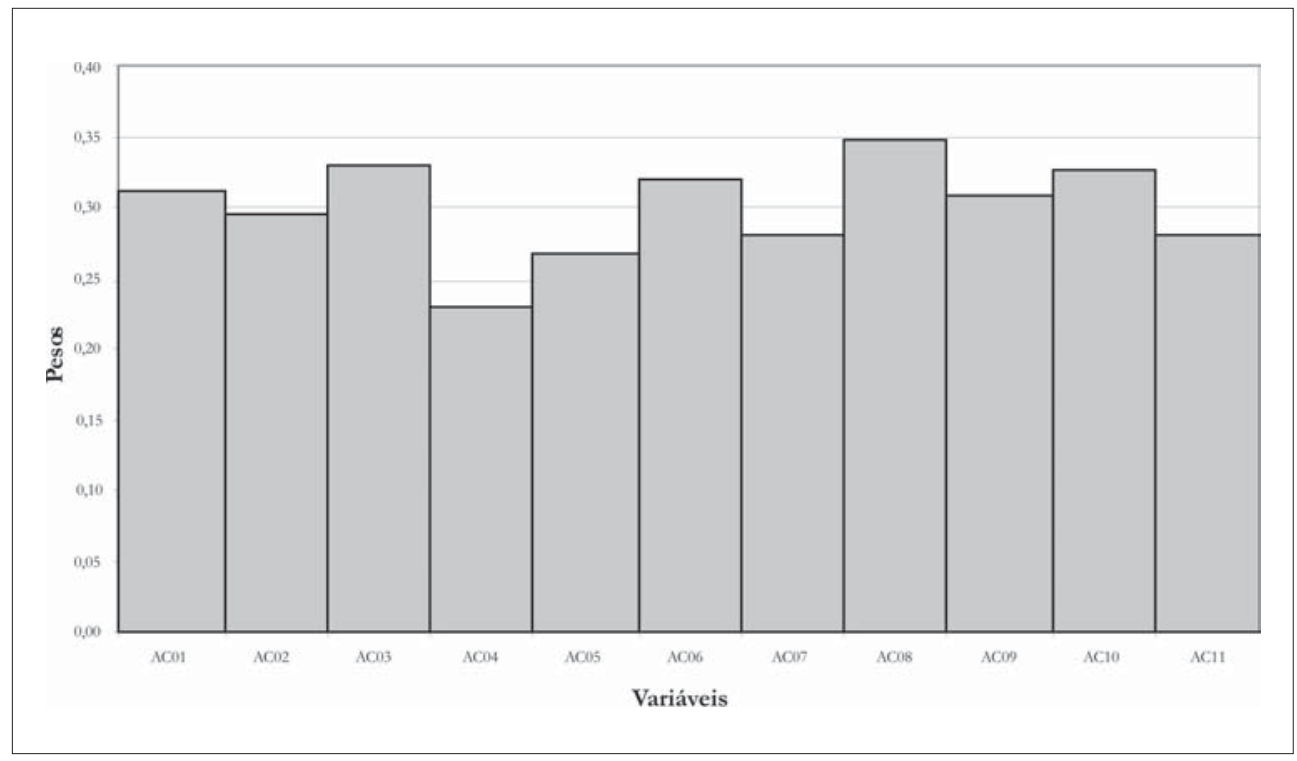

Fonte: Elaboração do autor

Gráfico 3: Pesos atribuídos às variáveis no cálculo do Subíndice de Ação Cultural 
de Fortalecimento Institucional e Gestão Democrática aqui desenvolvido.

Como se pode observar, a maioria dos municípios localiza-se nas regiões Sul e Sudeste. O município de Natividade (TO) foi o único entre os dez primeiros, segundo esse índice, que fica fora de tais regiões. A título de ilustração, a Tabela 2 é apresentada. Ela compara os atributos do município de Natividade (TO) com os da cidade do Rio de Janeiro (RJ) e ajuda a explicar por que o primeiro município entra no ranking dos dez melhores e o segundo, não.

Em termos de unidades federativas ${ }^{4}$, o Distrito Federal possui o melhor desempenho nesse índice, seguido por Minas Gerais, Mato Grosso, Mato Grosso do Sul e Ceará. Deve-se destacar o Estado de Minas Gerais, no qual aproximadamente $70 \%$ dos municípios estão acima da média nacional em relação ao fortalecimento institucional na gestão de cultura.

A Tabela 3 apresenta a classificação dos municípios segundo o Subíndice de Infraestrutura e Recursos Humanos. Como já mencionado, esse subíndice é fortemente influenciado pela disponibilidade de recursos humanos no órgão gestor de cultura.

As melhores médias entre as unidades federativas foram obtidas, respectivamente, pelo Distrito Federal, Rio de Janeiro, Mato Grosso do Sul, Santa Catarina e São Paulo. Vale a pena também destacar os estados do Rio Grande do Sul, Espírito Santo, Rondônia, Paraná e Bahia, que, apesar de não fazerem parte do grupo com as melhores médias, possuem mais de $50 \%$ dos seus municípios com valores acima da média nacional para o índice.

Tabela 1: Municípios com os maiores valores no Subíndice de Fortalecimento Institucional e Gestão Democrática

\begin{tabular}{l|l|l|c}
\hline \multicolumn{1}{c|}{ Código IBGE } & UF & \multicolumn{1}{c|}{ Município } & Índice FI \\
\hline 430510 & RS & Caxias do Sul & 212,35 \\
\hline 410430 & PR & Campo Mourão & 209,59 \\
\hline 411990 & PR & Ponta Grossa & 208,83 \\
\hline 350380 & SP & Artur Nogueira & 200,16 \\
\hline 350950 & SP & Campinas & 198,83 \\
\hline 354780 & SP & Santo André & 198,37 \\
\hline 420820 & SC & Itajaí & 196,23 \\
\hline 315180 & MG & Poços de Caldas & 195,84 \\
\hline 171420 & TO & Natividade & 195,20 \\
\hline 352240 & SP & Itapeva & 193,72 \\
\hline
\end{tabular}

Fonte: Elaboração do autor 
Tabela 2: Comparação dos atributos dos municípios

Natividade - TO x Rio de Janeiro - RJ

\begin{tabular}{|c|c|c|}
\hline Variável & Natividade-TO & Rio de Janeiro - RJ \\
\hline $\begin{array}{l}\text { Característica do órgão municipal } \\
\text { gestor de cultura }\end{array}$ & $\begin{array}{l}\text { Secretaria municipal em } \\
\text { conjunto com outras políticas }\end{array}$ & $\begin{array}{l}\text { Secretaria municipal } \\
\text { exclusiva }\end{array}$ \\
\hline Existência de politica municipal de cultura & Sim & Não \\
\hline $\begin{array}{l}\text { Adesão do município ao Sistema } \\
\text { Nacional de Cultura }\end{array}$ & Sim & Não \\
\hline $\begin{array}{l}\text { Participação em consórcios intermunicipais } \\
\text { de cultura }\end{array}$ & Não & Não \\
\hline $\begin{array}{l}\text { Existência, estado e elaboração do } \\
\text { Plano Municipal ou Intermunicipal de Cultura }\end{array}$ & Em execução & Não existe \\
\hline $\begin{array}{l}\text { Participação social na elaboração do } \\
\text { Plano Municipal ou Intermunicipal de Cultura }\end{array}$ & Sim & - \\
\hline $\begin{array}{l}\text { Existência e aplicação de Lei Municipal de } \\
\text { fomento à cultura }\end{array}$ & Não & Sim \\
\hline $\begin{array}{l}\text { Existência de Lei Municipal de proteção ao } \\
\text { patrimônio histórico }\end{array}$ & $\operatorname{Sim}$ & Sim \\
\hline $\begin{array}{l}\text { Existência e periodicidade dos encontros do } \\
\text { Conselho Municipal de Cultura }\end{array}$ & Sim. Encontros mensais. & Não \\
\hline Estrutura do Conselho Municipal de Cultura & Conselho paritário & Não \\
\hline $\begin{array}{l}\text { Escolha dos participantes do Conselho } \\
\text { Municipal de Cultura advindos da sociedade civil }\end{array}$ & $\begin{array}{l}\text { Indicação: poder público e } \\
\text { sociedade civil }\end{array}$ & Não \\
\hline $\begin{array}{l}\text { Diversificação da representação da sociedade civil } \\
\text { no Conselho Municipal de Cultura }\end{array}$ & Representantes de sete setores & Não \\
\hline $\begin{array}{l}\text { Diversificação das atribuições do } \\
\text { Conselho Municipal de Cultura }\end{array}$ & 11 atribuições. & Não \\
\hline $\begin{array}{l}\text { Existência e periodicidade dos encontros do } \\
\text { Conselho Municipal de Preservação do Patrimônio }\end{array}$ & Sim. Encontros mensais & $\begin{array}{l}\text { Sim. } \\
\text { Encontros mensais. }\end{array}$ \\
\hline $\begin{array}{l}\text { Estrutura do Conselho de Preservação } \\
\text { do Patrimônio }\end{array}$ & Conselho paritário & Conselho paritário \\
\hline $\begin{array}{l}\text { Escolha dos participantes do Conselho Municipal de } \\
\text { Preservação do Patrimônio advindos da sociedade civil }\end{array}$ & $\begin{array}{l}\text { Indicação: poder público e } \\
\text { sociedade civil }\end{array}$ & $\begin{array}{l}\text { Indicação pelo } \\
\text { poder público }\end{array}$ \\
\hline $\begin{array}{l}\text { Diversificação da representação da sociedade civil no } \\
\text { Conselho Municipal de Preservação do Patrimônio }\end{array}$ & Representantes de três setores & $\begin{array}{l}\text { Representantes de } \\
\text { dois setores }\end{array}$ \\
\hline $\begin{array}{l}\text { Diversificação das atribuições do Conselho Municipal } \\
\text { de Preservação do Patrimônio }\end{array}$ & 10 atribuições & 7 atribuições \\
\hline $\begin{array}{l}\text { Existência e exclusividade do } \\
\text { Fundo Municipal de Cultura }\end{array}$ & Fundo exclusivo para a Cultura & Não \\
\hline Administração do Fundo Municipal de Cultura & $\begin{array}{l}\text { Colegiado com participação da } \\
\text { sociedade civil }\end{array}$ & Não \\
\hline $\begin{array}{l}\text { A seleção de projetos a serem financiados pelo } \\
\text { Fundo Municipal de Cultura inclui concursos ou } \\
\text { editais públicos }\end{array}$ & Sim & Não \\
\hline
\end{tabular}

Fonte: Elaboração do autor 
Tabela 3: Municípios com os maiores valores no Subíndice de Infraestrutura e Recursos Humanos

\begin{tabular}{l|c|l|c}
\hline Código IBGE & UF & Município & Índice IH \\
\hline 330452 & RJ & Rio das Ostras & 195,14 \\
\hline 330130 & RJ & Casimiro de Abreu & 190,25 \\
\hline 354140 & SP & Presidente Prudente & 189,07 \\
\hline 313190 & MG & Itabirito & 185,60 \\
\hline 410370 & PR & Cambé & 181,87 \\
\hline 330240 & RJ & Macaé & 181,38 \\
\hline 354850 & SP & Santos & 181,22 \\
\hline 430010 & RJ & Angra dos Reis & 179,66 \\
\hline 355070 & PR & Campo Mourão & 179,46 \\
\hline
\end{tabular}

Fonte: Elaboração do autor

A Tabela 4 mostra os dez melhores municípios segundo o Subíndice de Ação Cultural. Recife lidera o ranking sendo, no entanto, o único município nordestino a fazer parte do grupo dos dez melhores, que é dominado por cidades paulistas (4), paranaenses (3) e gaúchas (2).

É interessante notar que São Paulo, Paraná e Rio Grande do Sul possuem um padrão municipal muito concentrado no concernente à ação cultural. Isso pode ser observado a partir do fato de que, apesar de contarem com muitos municípios na lista dos dez mais, as suas médias estaduais não constam entre as cinco mais altas, que são aquelas referentes às unidades federativas do Distrito Federal, Rio de Janeiro, Ceará, Espírito Santo e Pernambuco.

A Tabela 5 apresenta os dez municípios com os maiores valores no Índice Municipal de Gestão Cultural completo. Como ressaltado anteriormente, este índice foi obtido a partir da média aritmética dos outros índices padronizados.

A classificação é dominada por cidades de porte médio ou grande e aparecem apenas duas capitais: Recife e São Paulo. Outro ponto de destaque é que existe apenas um representante de fora das regiões Sul e Sudeste nessa classificação: a cidade de Recife.

\section{Aplicações do índice e conclusões}

A existência de um índice de gestão, como o IGMC, pode auxiliar a administração cultural dos municípios brasileiros em diversos aspectos. O primeiro deles diz respeito ao acompanhamento puro e simples da evolução do indicador com fins de acompanhamento dos resultados. Esse acompanhamento poderia dar pistas não só da efetividade das políticas municipais, mas também daquelas mais abrangentes de cunho federal ou estadual. 
Tabela 4: Municípios com os maiores valores no Subíndice de Ação Cultural

\begin{tabular}{l|l|l|l}
\hline Código IBGE & UF & \multicolumn{1}{|c}{ Município } & AC Index \\
\hline 261160 & PE & Recife & 192,36 \\
\hline 430210 & RS & Bento Gonçalves & 186,88 \\
\hline 410690 & PR & Curitiba & 182,08 \\
\hline 354980 & SP & São José do Rio Preto & 180,51 \\
\hline 431740 & RS & Santiago & 180,06 \\
\hline 411370 & PR & Londrina & 179,86 \\
\hline 355030 & SP & São Paulo & 178,89 \\
\hline 411990 & PR & Ponta Grossa & 178,79 \\
\hline 354890 & SP & São Carlos & 177,70 \\
\hline 354870 & SP & São Bernardo do Campo & 176,92 \\
\hline
\end{tabular}

Fonte: Elaboração do autor

Tabela 5: Municípios com os maiores valores no Índice Municipal de Gestão Cultural

\begin{tabular}{l|l|l|l}
\hline Código IBGE & UF & Município & IMGC \\
\hline 430510 & RS & Caxias do Sul & 179,51 \\
\hline 354850 & SP & Santos & 179,40 \\
\hline 410430 & PR & Campo Mourão & 179,16 \\
\hline 261160 & PE & Recife & 172,86 \\
\hline 411990 & PR & Ponta Grossa & 172,17 \\
\hline 420910 & SC & Joinville & 172,11 \\
\hline 355030 & SP & São Paulo & 169,34 \\
\hline 354140 & SP & Presidente Prudente & 168,96 \\
\hline 420820 & SC & Itajaí & 168,55 \\
\hline 411370 & PR & Londrina & 167,89 \\
\hline
\end{tabular}

Fonte: Elaboração do autor 
A análise dos resultados individuais pode dar ensejo a recomendações específicas sobre quais políticas poderiam melhorar a gestão cultural de determinado município. Dessa forma, o IGMC poderia ser utilizado a priori para avaliar a eficiência de determinada ação.

Assim, um sistema de diagnóstico da gestão cultural poderia ser desenvolvido com base no índice. Seu princípio de funcionamento seria o seguinte: dada a situação da gestão cultural de um determinado município, avaliada pela magnitude do IGMC, as ações teriam maior impacto na evolução do índice.

Também poder-se-iam ponderar tais ações pela dificuldade de execução, tomando-se como parâmetro a frequência das já implementadas em municípios comparáveis, sendo que tal comparabilidade poderia ser definida por diversas variáveis (faixa de população, região geográfica etc.) escolhidas pelo próprio gestor municipal, ou pelo analista que estiver utilizando o sistema.

Essas são apenas algumas das aplicações possíveis, as quais não descartam tantas outras a serem ainda planejadas. O mais importante é que um índice como o IGMC não seja apenas encarado como ferramenta para a criação de rankings, mas sim um instrumento que pode ser muito útil no desenvolvimento da gestão e da própria cultura nacional.

(Artigo recebido em agosto de 2009. Versão final em setembro de 2009).

\section{Notas}

1 Suponha que haja dois valores $\mathrm{a}_{1}=1$ metro e $\mathrm{a}_{2}=2$ metros. Então a média entre eles é ã $=$ 1,5 metros e a sua variância, $\operatorname{Var}(\mathrm{a})=0,25$ metros ao quadrado. Se esta variável for medida em centímetros, ter-se-ia, $a_{1}=100 \mathrm{~cm} \mathrm{e} a_{2}=200 \mathrm{~cm}, \tilde{a}=150 \mathrm{~cm}$ e $\operatorname{Var}(\mathrm{a})=2.500 \mathrm{~cm}$ ao quadrado.

2 Foi detectada uma incorreção na base da Munic para este item. Onde lá se lê "de 3 a mais de 10 ", dever-se-ia ler "de 3 a 6 ".

3 Os dados obtidos a partir do CD da Munic apresentam erros quanto aos rótulos de algumas variáveis. Por exemplo, as variáveis apresentadas na planilha "Dicionário" da publicação com os rótulos A432, A435 e A438 encontram-se na planilha "Equipamentos" sob os rótulos A433, A436 e A439, respectivamente. Para efeitos deste artigo foram utilizados os rótulos do banco de dados encontrado na planilha "Equipamentos".

4 Os desempenhos das UF foram calculados a partir da média simples dos municípios.

\section{Referências bibliográficas}

Brasil. Plano nacional de cultura - Diretriz̨es gerais. Ministério da Cultura, $2^{\underline{a}}$ edição, Brasilia, 2008. Dunteman, G.H. Principal component analysis. Sage Publications, 1989.

Instituto Brasileiro de Geografia e Estatística (IBGE). Perfil dos municípios brasileiros - Cultura 2006. Rio de Janeiro, 2007. 
JaCKson, J.E. A User's guide to principal components. Wiley Series in Probapility and Statistics. 2003.

Mingoti, S.A. Análise de dados através de métodos de estatística multivariada: uma abordagem aplicada. Editora UFMG, 1aㅡ reimpressão, Belo Horizonte, 2007.

Silva, F.A.B., Araújo, H.E., Carvalho, A.X.Y., Diniz, B.P.C, Vaz, F.M., Silveira, F.G. e Camargo, R.S. Índice municipal de desenvolvimento cultural - Idcult-M. Ipea, Brasília, 2008.

Silva, F.A.B., Araújo, H.E., SouzA, A.L. Emprego formal no setor cultural-1994-2002. Ipea, Texto para Discussão n. 1276. Brasília - DF. 2007. 


\section{Resumo-Resumen-Abstract}

\section{Índice de Gestão Municipal em Cultura Rogério Boueri}

O objetivo deste trabalho é o de construir um índice de gestão municipal em cultura, com o potencial de servir de balizador para as ações na área, promovidas nas esferas municipal, estadual e federal.

Para tanto, são utilizados dados do "Perfil dos Municípios Brasileiros - Cultura 2006", publicado pelo IBGE, o qual dispõe de informações de 5.562 municípios sobre cultura e gestão cultural. As respostas foram tabuladas e combinadas de forma a produzir variáveis específicas para a construção do índice.

O método utilizado para a elaboração do Índice de Gestão Municipal em Cultura (IGMC) foi o de análise de componentes principais, que permite à própria amostra definir os pesos que cada variável exercerá na computação do índice final. Além do IGMC geral, foram utilizados no processo três subíndices, cada um deles procurando refletir um aspecto específico da gestão municipal em cultura, a saber: fortalecimento institucional e gestão democrática, infraestrutura e recursos humanos, e ação cultural.

Os resultados obtidos permitem diversos tipos de comparações intermunicipais e regionais, bem como a prescrição de ações locais na área de gestão que visem à melhoria da administração cultural dos municípios.

Palavras-chave: gestão cultural, gestão municipal, análise de componentes principais.

\section{Índice de Gerencia Municipal en Cultura}

\section{Rogério Boueri}

El objetivo de este trabajo es construir un índice de la gerencia municipal en cultura, con el potencial de servir de guía para las acciones en esta área para las municipalidades cuanto para las provincias y para el gobierno federal.

Son utilizados con este objetivo, los dados del "Perfil de las Ciudades Brasileñas - Cultura 2006", publicados por el Instituto Brasileño de Geografía e Estadística - IBGE, que hace uso de las respuestas de 5.562 ciudades sobre cultura y gerencia cultural. Las respuestas habían sido tabuladas y combinadas de forma a producir variables específicas para la construcción del índice.

El método usado para la construcción del Índice de Gerencia Municipal en Cultura (IGMC) fue el análisis de componentes principales, que permite que la propia muestra defina los pesos que cada una de las variables ejercerán en el cómputo del índice final. En adición al IGMC general, también tres subíndices fueran computados en el proceso, cada uno de ellos buscando reflejar un aspecto específico de la gerencia municipal en cultura, a saber: fortalecimiento de las instituciones, infraestructura y recursos materiales y acción cultural.

Los resultados conseguidos permiten diversos tipos de comparaciones Inter-municipales y Inter-regionales, así como la prescripción de acciones locales en el área de la gerencia cultural que tienen como objetivo la mejora de la administración cultural de las ciudades.

Palabras clave: gerencia cultural, gerencia de las municipalidades, análisis de componentes principales. 


\section{Municipal Index of Culture Management}

Rogério Boueri

In this article it is described the formulation of an index of cultural management for the Brazilian municipalities, which may be utilized as a guide for policy not only by municipal authorities, but also for their state and federal counterparts.

Principal Component Analysis (PCA) was used to build such index, which was named as Municipal Index of Culture Management (IGMC). PCA allows that the weights attached to each variable of the index must be chosen accordingly the values contained in the sample itself, thus reducing the level of arbitrariness. Beyond the general IGMC, three sub indexes were also formulated, each one seeking to reflect one distinct aspect of the municipal management: the sub index of Institutional Enhancement and Democratic Management, the sub index of Infrastructure and Human Resources and the sub index of Cultural Action.

The obtained results allow multiples comparisons among municipalities, states and regions, as well as, the prescription of local policies that aims to enhance the cultural management at the municipal level.

Keywords: Cultural management, municipal management, principal components analysis.

Rogerio Boueri

Professor da Universidade Católica de Brasília e economista do Ipea. Contato: rogério.boueri@ipea.gov.br 


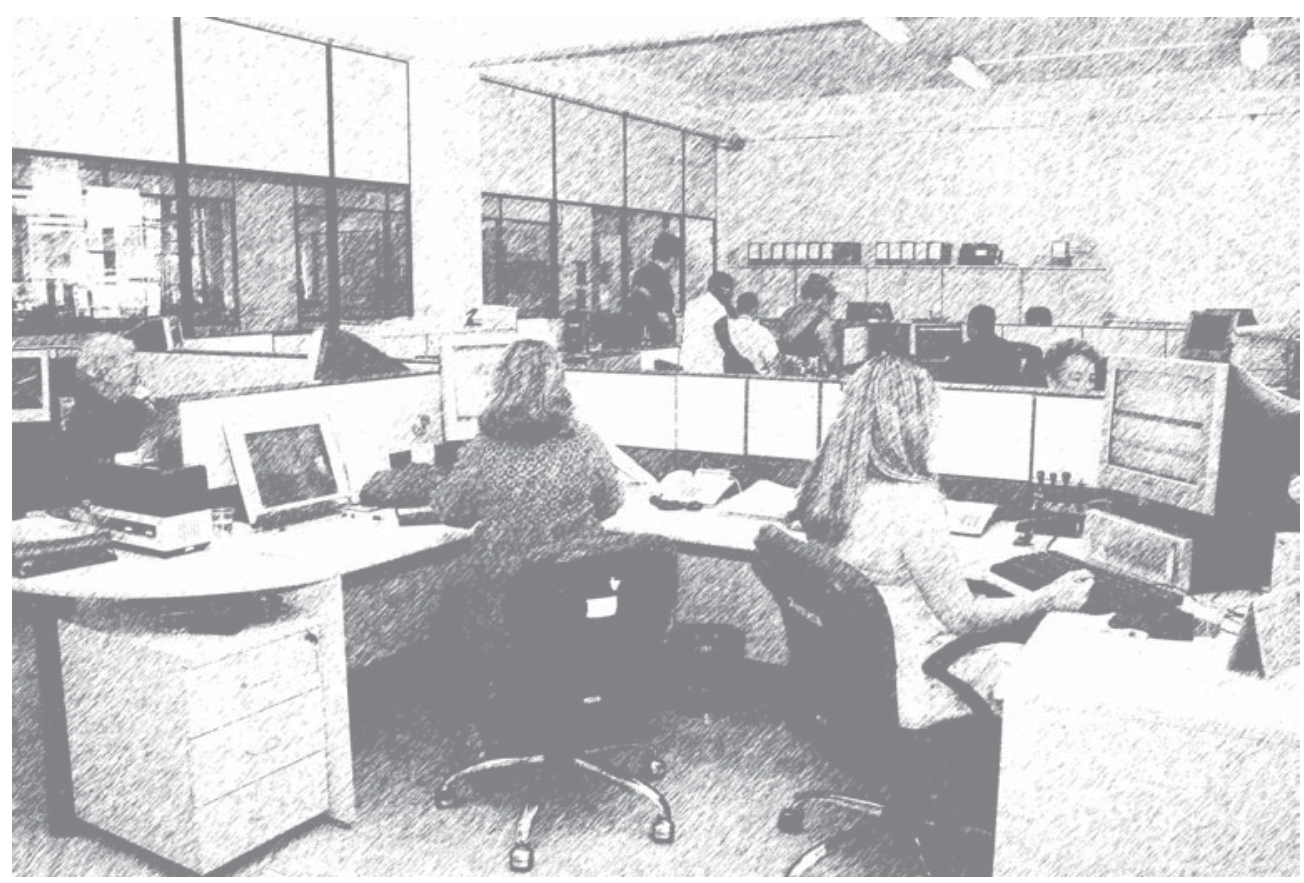

